\title{
A INCLUSÃO ESCOLAR DE ALUNOS SURDOS: O QUE DIZEM ALUNOS, PROFESSORES E INTÉRPRETES SOBRE ESTA EXPERIÊNCIA
}

\author{
Cristina Broglia Feitosa de Lacerda*
}

\begin{abstract}
RESUMO: Este artigo focaliza uma experiência de inclusão de aluno surdo em escola regular, com a presença de intérprete de língua de sinais. Alunos, professores e intérpretes envolvidos foram entrevistados e seus depoimentos analisados. Os dados indicam problemas que ocorrem no espaço escolar, alguns identificados pelos entrevistados como desconhecimento sobre a surdez e sobre suas implicações educacionais, dificuldades na interação professor/intérprete e a incerteza em relação ao papel dos diferentes atores neste cenário. Os depoimentos apontam ainda dificuldades com adaptaçôes curriculares e estratégias de aula, exclusão do aluno surdo de atividades. Todavia, tais aspectos são negligenciados, já que há um pressuposto tácito de que a inclusão escolar é um bem em si. Pretende-se contribuir para a reflexão acerca de práticas inclusivas envolvendo surdos, procurando compreender seus efeitos, limites e possibilidades e buscando uma atitude educacional responsável e conseqüente frente a este grupo.
\end{abstract}

Palavras-chave: Inclusão escolar. Surdez. Intérprete de Língua Brasileira de Sinais.

SCHOOL INCLUSION OF DEAF STUDENTS: WHAT STUDENTS, TEACHERS AND INTERPRETERS SAY ABOUT THIS EXPERIENCE

ABSTRACT: This paper focuses on the experience of deaf student inclusion in a regular school, with the presence of sign language interpreters. The students, teachers and interpreters involved were interviewed and their statements were analyzed. These data describes the problems occurring at school as ignorance on deafness

* Doutora em Educação e docente do Programa de Pós-Graduação em Educação e do Curso de Fonoaudiologia da Universidade Metodista de Piracicaba (UnIMEP). E-mail: cristinalacerda@uol.com.br 
A inclusão escolar de alunos surdos: o que dizem alunos, professores e intérpretes...

and its educational implications, difficulties in the professor/interpreter interaction and uncertainty about the role of the different actors involved. They also highlight difficulties with curricular adaptations and class strategies, and the exclusion of the deaf student from activities. Nevertheless, such aspects are disregarded because it is tacitly assumed that school inclusion is good in itself. We intend to contribute to a reflection about inclusive practices involving the deaf, seeking to understand their effects, limits and possibilities and looking for a responsible and coherent educational attitude toward this group.

Key words: School inclusion. Deafness. Brazilian sign language interpreter.

\section{Introdução}

A

educação de pessoas surdas é um tema bastante preocupante. Pesquisas desenvolvidas no Brasil e no exterior indicam que um número significativo de sujeitos surdos que passaram por vários anos de escolarização apresenta competência para aspectos acadêmicos muito aquém do desempenho de alunos ouvintes, apesar de suas capacidades cognitivas iniciais serem semelhantes. Uma evidente inadequação do sistema de ensino é denunciada por estes dados, revelando a urgência de medidas que favoreçam o desenvolvimento pleno destas pessoas.

No mundo todo, a partir da década de 1990, difundiu-se com força a defesa de uma política educacional de inclusão dos sujeitos com necessidades educativas especiais, propondo maior respeito e socialização efetiva destes grupos e contemplando, assim, também a comunidade surda. Houve um movimento de desprestigio dos programas de educação especial e um incentivo maciço para práticas de inclusão de pessoas surdas em escolas regulares (de ouvintes).

Desse modo, diversas têm sido as formas de realização da inclusão. Todavia, é inegável que a maioria dos alunos surdos sofreu uma escolarização pouco responsável. Este artigo pretende, então, a partir de uma experiência de inclusão de aluno surdo em uma escola regular, com a presença de intérprete de língua de sinais, focalizar e avaliar aspectos dessa experiência do ponto de vista de alunos surdos e ouvintes, intérpretes e professores implicados nesta vivência. Para tal, foram realizadas entrevistas com estes sujeitos e analisados seus depoimentos. 


\section{Surdez, linguagem e inclusão escolar}

A linguagem é responsável pela regulação da atividade psíquica humana, pois é ela que permeia a estruturação dos processos cognitivos. Assim, é assumida como constitutiva do sujeito, pois possibilita interações fundamentais para a construção do conhecimento (Vigotski, 2001). A linguagem é adquirida na vida social e é com ela que o sujeito se constitui como tal, com suas características humanas, diferenciando-se dos demais animais. É no contato com a linguagem, integrando uma sociedade que faz uso dela, que o sujeito a adquire. Já para as pessoas surdas, esse contato revela-se prejudicado, pois a língua oral é percebida por meio do canal auditivo, alterado nestas pessoas.

Assim, os sujeitos surdos pela defasagem auditiva enfrentam dificuldades para entrar em contato com a língua do grupo social no qual estão inseridos (Góes, 1996). Desse modo, no caso de crianças surdas, o atraso de linguagem pode trazer conseqüências emocionais, sociais e cognitivas, mesmo que realizem aprendizado tardio de uma língua.

Devido às dificuldades acarretadas pelas questóes de linguagem, observa-se que as crianças surdas encontram-se defasadas no que diz respeito à escolarização, sem o adequado desenvolvimento e com um conhecimento aquém do esperado para sua idade. Disso advém a necessidade de elaboração de propostas educacionais que atendam às necessidades dos sujeitos surdos, favorecendo o desenvolvimento efetivo de suas capacidades.

Partindo do conhecimento sobre as línguas de sinais, amplamente utilizadas pelas comunidades surdas, surge a proposta de educação bilíngüe que toma a língua de sinais como própria dos surdos, sendo esta, portanto, a que deve ser adquirida primeiramente. É a partir desta língua que o sujeito surdo deverá entrar em contato com a língua majoritária de seu grupo social, que será, para ele, sua segunda língua. Assim, do mesmo modo que ocorre quando as crianças ouvintes aprendem a falar, a criança surda exposta à língua de sinais irá adquiri-la e poderá desenvolver-se, no que diz respeito aos aspectos cognitivos e lingüísticos, de acordo com sua capacidade. A proposta de educação bilíngüe, ou bilingüismo, como é comumente chamada, tem como objetivo educacional tornar presentes duas línguas no contexto escolar, no qual estão inseridos alunos surdos.

Discutir a educação de surdos implica discutir também o tema inclusão escolar, tratado mundialmente. Na década de 1990, muitos países 
A inclusão escolar de alunos surdos: o que dizem alunos, professores e intérpretes...

assumiram a inclusão como tarefa fundamental da educação pública e diferentes tentativas foram colocadas em prática buscando viabilizá-la. Estudiosos como Bunch (1994), Cohen (1994) e Kirchner (1994), no exterior, e Silveira Bueno (1994), Massota (1996) e Sassaki (1997), no Brasil, entre outros, argumentam que todos os alunos devem ter as mesmas oportunidades de freqüentar classes regulares próximas à sua moradia, defendem a necessidade de um programa educacional adequado às capacidades dos diferentes alunos, e que promova desafios a todas as crianças atendidas. Destacam também a importância de oferecimento de suporte e assistência às crianças com necessidades especiais e aos professores, para que o atendimento seja o melhor possível.

A defesa deste modelo educacional se contrapõe ao modelo anterior de educação especial, que favorecia a estigmatização e a discriminaçãao. $\mathrm{O}$ modelo inclusivo sustenta-se em uma filosofia que advoga a solidariedade e o respeito mútuo às diferenças individuais, cujo ponto central está na relevância da sociedade aprender a conviver com as diferenças. Contudo, muitos problemas são enfrentados na implementação desta proposta, já que a criança com necessidades especiais é diferente, e o atendimento às suas características particulares implica formação, cuidados individualizados e revisōes curriculares que não ocorrem apenas pelo empenho do professor, mas que dependem de um trabalho de discussão e formação que envolve custos e que tem sido muito pouco realizado.

A inclusão apresenta-se como uma proposta adequada para a comunidade escolar, que se mostra disposta ao contato com as diferenças, porém não necessariamente satisfatória para aqueles que, tendo necessidades especiais, necessitam de uma série de condiçóes que, na maioria dos casos, não têm sido propiciadas pela escola.

Antia e Stinson (1999) assumem a tarefa de confrontar diversos estudos sobre a inclusão, ilustrando a evolução das discussōes nesta área. Referem-se a várias experiências de inclusão de crianças surdas, nas quais a almejada integração social e acadêmica não ocorre efetivamente. $\mathrm{O}$ problema central, segundo os estudos, é o acesso à comunicação, já que são necessárias intervenções diversas (boa amplificação sonora, tradução simultânea, apoio de intérprete, entre outros), que nem sempre tornam acessíveis os conteúdos tratados em classe. A dificuldade maior está em oportunizar uma cultura de colaboração entre alunos surdos e ouvintes, e que professores e especialistas que participam da atividade escolar constituam uma equipe com tempo reservado para organização de ativida- 
des, trabalhando conjuntamente numa ação efetiva de proposição de atividades que atendam às necessidades de todos os alunos. Outro ponto abordado é a necessidade de participação de membros da comunidade surda na escola, favorecendo o desenvolvimento de aspectos da identidade surda dessas crianças. Antia e Stinson (op. cit.) argumentam que uma inclusão nestes moldes pode efetivamente beneficiar todos os alunos envolvidos, mas esta não é freqüentemente desenvolvida.

As reflexões apresentadas referem-se à realidade de diversos países que, rompendo com as premissas da medicalização ou da segregação e buscando uma escola para todos, discutem modelos de educação inclusiva capazes de atender às diferenças. Entretanto, vários destes estudos, realizados em países do primeiro mundo, com condições gerais de educação satisfatórias, indicam dificuldades de implantação dessas propostas, que são definidas legalmente de forma ideal, mas que na prática são de difícil implementação.

\section{Refletindo sobre aspectos da inclusão no Brasil}

O movimento da chamada educação inclusiva, que emerge apoiado pela Declaração de Salamanca ${ }^{1}$ (1994), defende o compromisso que a escola deve assumir de educar cada estudante, contemplando a pedagogia da diversidade, pois todos os alunos deverão estar dentro da escola regular, independente de sua origem social, étnica ou lingüística. Assim, de acordo com Mazzota (1996), a implementação da inclusão tem como pressuposto um modelo no qual cada criança é importante para garantir a riqueza do conjunto, sendo desejável que na classe regular estejam presentes todos os tipos de aluno, de tal forma que a escola seja criativa no sentido de buscar soluções visando manter os diversos alunos no espaço escolar, levando-os a obtenção de resultados satisfatórios em seu desempenho acadêmico e social.

A inclusão escolar é vista como um processo dinâmico e gradual, que pode tomar formas diversas a depender das necessidades dos alunos, já que se pressupõe que essa integração/inclusão possibilite, por exemplo, a construção de processos lingüísticos adequados, de aprendizado de conteúdos acadêmicos e de uso social da leitura e da escrita, sendo o professor responsável por mediar e incentivar a construção do conhecimento através da interação com ele e com os colegas. 
A inclusão escolar de alunos surdos: o que dizem alunos, professores e intérpretes...

Botelho (1998) e Lacerda (2000), entre outros autores, alertam para o fato de que o aluno surdo, freqüentemente, não compartilha uma língua com seus colegas e professores, estando em desigualdade lingüística em sala de aula, sem garantia de acesso aos conhecimentos trabalhados, aspectos estes, em geral, não problematizados ou contemplados pelas práticas inclusivas.

Laplane (2004) argumenta que acreditar que valores e princípios da educação inclusiva sejam capazes de promover instituições mais justas do que aquelas que fundamentaram a segregação, compreender que o discurso em defesa da inclusão se constituiu historicamente como oposto ao da segregação e, nesse contexto, reconhecer a importância de destacar as vantagens da educação inclusiva não pode ocultar os problemas todos que esta mesma "educação inclusiva" impōe. A autora defende que a questão central dos ideais da educação inclusiva se confronta com a desigualdade social presente no Brasil e em outros paises em desenvolvimento.

(...) A análise das tendências que marcam o processo de globalização não deixa dúvidas quanto aos valores que privilegia e aos modos como se organiza. No contexto do acirramento das diferenças sociais provocado pelas tendências globalizantes, pela concentração de riqueza e pelos processos que a acompanham (redução do emprego, encolhimento do Estado etc.), a implementação de políticas realmente inclusivas deve enfrentar grandes problemas.

O "elogio da inclusão" apresenta a vantagem de arrolar argumentos para a defesa das políticas inclusivas. Mas para que seja realmente eficaz é preciso que o discurso se feche sobre si próprio, aparecendo como uma totalidade que não admite questionamentos. (Laplane, 2004, p. 17-18)

A fragilidade das propostas de inclusão, neste sentido, residem no fato de que, freqüentemente, o discurso contradiz a realidade educacional brasileira, caracterizada por classes superlotadas, instalações físicas insuficientes, quadros docentes cuja formação deixa a desejar. Essas condiçôes de existência do sistema educacional põem em questão a própria idéia de inclusão como política que, simplesmente, propõe a inserção dos alunos nos contextos escolares presentes. Assim, o discurso mais corrente da inclusão a circunscreve no âmbito da educação formal, ignorando as relações desta com outras instituiçóes sociais, apagando tensões e contradiçốes nas quais se insere a política inclusiva, compreendida de forma mais ampla (Laplane, 2004). 


\section{Sobre a pesquisa}

A sala de aula focalizada como alvo desse estudo é uma quinta série do ensino fundamental, de uma escola da rede privada, que conta com 29 alunos ouvintes, uma criança surda e a presença de duas intérpretes de língua de sinais que se revezam neste trabalho. A faixa etária dos alunos varia de 10 a 12 anos, sendo 17 meninas e 12 meninos. A criança surda é acompanhada, desde os 6 anos de idade, de intérprete educacional contratada e paga pela família. Ela freqüenta esta escola há um ano e meio; é a primeira experiência com aluno surdo e intérprete em sala de aula desta instituição. A criança, com 12 anos de idade, é portadora de surdez profunda bilateral, adquirida por meningite aos 3 anos de idade. Filha de pais ouvintes, não tem domínio do português falado e é usuária da Língua Brasileira de Sinais (LIBRAS).

Quando da entrada do aluno surdo nesta escola, a direção se mostrou interessada pelo processo de inclusão com a presença de intérprete de LIBRAS e afirmou que seria feito um trabalho conjunto para o sucesso da inclusão: coordenação, professores, intérprete, família, fonoaudióloga e alunos. Todavia, após o início do ano letivo, poucos encontros ocorreram, sendo inicialmente mensais, e durante a quinta série só ocorreram encontros mediante a solicitação das intérpretes e da fonoaudióloga. A escola julgava a inclusão bastante satisfatória e não via necessidade de discussões.

Apesar das solicitações feitas pelas intérpretes e pela fonoaudióloga do aluno surdo, não foram realizadas reuniões de planejamento para oferecer mais informaçóes sobre a surdez, sobre o aluno surdo, sobre a adequação das estratégias em sala de aula e sobre o papel do intérprete aos novos professores da quinta série. A direção escolar prometeu tais reuniões, mas não as realizou, alegando falta de horário disponível.

$\mathrm{Na}$ quinta série focalizada, são oito os professores responsáveis pelas diversas disciplinas ministradas: Português, Matemática, Inglês, Ciências, Geografia, História, Educação Física e Artes. As aulas têm a duração de 50 minutos. As dinâmicas de aula variam de acordo com cada professor e com os conteúdos, mas há um predomínio de aulas expositivas com uso preferencial do quadro negro como apoio para as explicaçōes. Eventualmente, são usados recursos como vídeos, mapas ou transparências. 
A inclusão escolar de alunos surdos: o que dizem alunos, professores e intérpretes...

Em geral, os alunos assistem e participam respondendo a perguntas em aulas expositivas, mas com alguma freqüência são realizadas atividades em grupo. Os grupos se alternam bastante e não têm uma configuração estável.

O aluno surdo estava sempre acompanhado de uma das intérpretes (que se revezavam em dias alternados da semana) e esta se sentava ao seu lado, ou na frente da classe, dependendo do tipo de atividade proposta.

$\mathrm{Na}$ realidade brasileira, são poucas as pessoas com formação específica para atuarem como intérpretes da LIBRAS. Tem crescido o número de cursos oferecidos, todavia eles se concentram nos grandes centros, atingindo um número restrito de pessoas. Desse modo, é difícil encontrar, em cidades do interior, pessoas com formação específica como intérprete da LIBRAS e que se disponham a atuar como intérprete educacional, já que este trabalho exige dedicação de muitas horas semanais, com horários fixos. Assim, as duas intérpretes entrevistadas foram pessoas que aceitaram trabalhar nas condições necessárias ao trabalho escolar, tinham um bom conhecimento da LIBRAS, interesse/capacitação para trabalhar no âmbito pedagógico e disponibilidade de horários.

\section{Entrevista e sujeitos entrevistados}

Para o estudo, foi realizado um esclarecimento sobre objetivos e procedimentos para: direção e coordenação da escola, professores, alunos ouvintes, aluno surdo, famílias dos alunos ouvintes, família do aluno surdo e intérpretes. As intérpretes foram entrevistadas separadamente, cada uma em dia e horário previamente combinados, fora do ambiente escolar. Mostraram-se interessadas em participar, especialmente porque queriam conhecer melhor sua própria realidade de trabalho, e não criaram dificuldades para a realização da entrevista.

Realizar a entrevista com os professores, entretanto, não foi tarefa fácil. Foram marcados diversos encontros na própria escola, em horários definidos por eles, já que alegaram não ter outro momento disponível a não ser aquele em que estavam na escola. Todavia, mesmo respeitando estes horários, o pesquisador não era atendido, por uma série de motivos: esquecimento, reuniões marcadas ao improviso e outros compromissos escolares, o que fez as entrevistas serem remarcadas 
muitas vezes. Ao final de várias tentativas, os próprios professores (aqueles mais participantes de discussões que envolviam o aluno surdo) propuseram que a entrevista fosse feita com dois deles, professora de português e professor de história, juntos, e diante das dificuldades tal proposta foi aceita.

Em relação aos alunos ouvintes, buscou-se sondar quais estariam mais disponíveis para participar de uma entrevista a partir de sugestôes do aluno surdo, intérpretes e família do aluno surdo. Tais alunos foram contatados, bem como suas famílias, e, depois de várias tentativas, uma das alunas sugeriu que o pesquisador fosse até a casa dela, pois convidaria uma outra colega de classe para que então fosse realizada a entrevista. As alunas se mostraram à vontade e participativas e julgou-se que os dados coletados foram bastante adequados aos propósitos da pesquisa.

O aluno surdo foi entrevistado pela pesquisadora e uma intérprete (diferente daquelas que o seguem em sala de aula, porém sua conhecida), para garantir que a comunicação em LiBRAs fosse satisfatória. A entrevista foi filmada para possibilitar a transcrição adequada da LIBRAS.

As entrevistas, no geral, duraram em média uma hora e meia cada uma; à exceção da entrevista com o aluno surdo, as demais foram gravadas em áudio. Todas foram transcritas integralmente para posterior análise.

\section{Professores}

O fluxo geral dos depoimentos aponta para a satisfação dos professores diante dos resultados dessa experiência, relatando que suas aulas transcorrem normalmente; que as presenças do aluno surdo e intérprete são facilmente assimiladas na rotina escolar; e que percebem um bom relacionamento entre os alunos e um bom rendimento geral do aluno surdo. Todavia, uma análise mais atenta do mesmo material revela paradoxalmente a falta de preparação para esta prática, desinformação geral acerca do argumento surdez e suas peculiaridades, ausência de planejamento de ações coordenadas que levem em conta a presença do intérprete e, talvez, o aspecto mais importante, a não consciência de que existem muitos problemas ocorrendo neste espaço, que mereceriam atenção e ações por parte dos professores.

Os professores referem-se a uma experiência que transcorre bem, que não causa estranhamento e que, portanto, não demanda ajustes e 
A inclusão escolar de alunos surdos: o que dizem alunos, professores e intérpretes...

pode ser mantida como está, porque os incômodos são mínimos e não merecem maior cuidado. A realidade é vista apenas parcialmente, esfumaçada, e isso parece garantir a tranqüilidade para o trabalho.

Porém, no próprio fluxo da entrevista os professores dão alguns sinais de que percebem, ainda que de maneira tênue, que algo precisa ser repensado: "Aquela história que nem maestro, a gente vê maestro erguer a mão numa orquestra, pensa que é chegar lá na frente, um sinalzinho...", diz o professor de História referindo-se ao trabalho da intérprete, demonstrando, ainda que fugazmente, perceber que há muito mais a ser compreendido. Os depoimentos da professora de Português falam de suas dúvidas e reflexões após o contato com informações mais aprofundadas sobre língua de sinais e educação de surdos, também indicando que percebe que há pontos obscuros que merecem ser repensados. Os depoimentos revelam e escondem problemas presentes nesta prática, mas, de maneira geral, os entrevistados referem-se à experiência como satisfatória.

\section{Alunos ouvintes}

Os depoimentos dos alunos ouvintes revelam que o aluno surdo é acolhido pela classe, visto com respeito e que conta com a amizade de vários companheiros. Entretanto, também revelam uma super valorização destas relaçōes, como se não houvesse problemas e como se tudo se desenvolvesse satisfatoriamente.

As alunas entrevistadas falam de um ambiente 'feliz', no qual o aluno é querido, tem boas relaçóes, e que todos conhecem sinais que são suficientes para uma comunicação eficiente. Neste ambiente, ele se mostra um bom aluno e o seu trabalho com a intérprete é acolhido sem dificuldades. Faz pensar em um ambiente tranqüilo, no qual não existem problemas. Entretanto, nos mesmos depoimentos, é possível perceber que a língua de sinais é vista como algo difícil, trabalhosa para aprender e que, às vezes, é um pouco chata; que o amigo surdo é 'legal', mas faz coisas estranhas que, freqüentemente, não são compreendidas e que se espera que ele aprenda a falar e fale.

Configura-se um paradoxo entre aquilo que parece importante que se acredite e aquilo que é efetivamente vivenciado. A relação entre alunos ouvintes e surdo não se revela sempre difícil, há aceitação e compreensão de suas características, mas não se revela sempre fácil, há dificuldades de 
relação, de conhecimento sobre a surdez e de aceitação de certas características. Porém, os aspectos mais difíceis da relação são ocultados, aparecendo apenas nas entrelinhas, percebidos como menos importantes. Há um saldo geral positivo e isso é o que conta. Também entre as crianças parece não haver estranhamento e apreensão em relação a essa experiência nova, que permita uma visão mais realística do que ocorre.

\section{Aluno surdo}

A leitura da entrevista do aluno surdo faz pensar que ele tenha uma compreensão particular de sua escolarização. Freqüentar uma classe de ouvintes não é uma opção para ele, mas algo normal e o único contexto escolar que conhece. Do mesmo modo, lhe parece normal ser acompanhado quotidianamente por uma intérprete, pois durante toda sua vida escolar teve ao seu lado alguém interpretando.

Em relação aos seus amigos, sabe que eles conhecem alguns sinais e os reconhece como tendo domínio da língua de sinais, proporcionando uma comunicação entre eles efetiva e sem maiores problemas. Reconhece que seus professores não conhecem sinais, mas isso não traz problemas, porque tem a intérprete ao seu lado que o ajuda em suas tarefas escolares. Não parece se sentir sozinho ou isolado. Vive em uma ilha, dentro de sua sala de aula, e isso lhe parece adequado; vê seu relacionamento restrito às intérpretes e às poucas trocas dialógicas com os alunos ouvintes como natural.

Entretanto, para aqueles que conhecem a vivência escolar entre crianças ouvintes, as possibilidades de trocas entre alunos e professores e a riqueza de informações que circulam quando se está em um grupo com o qual se compartilha uma mesma língua, a situação do aluno surdo parece insólita: em uma quinta série não conhece o nome dos amigos, não se relaciona diretamente com os professores, tem apenas um interlocutor efetivo no espaço escolar, está sempre acompanhado por um adulto, configurando uma situação que não pode ser chamada de satisfatória. Ele, provavelmente, por não conhecer outra realidade, mostra-se bem adaptado a sua situação. Como não conhece algo diferente, acredita que esta convivência seja plena e se satisfaz com ela. Cabe refletir se esta vivência escolar é realmente plena e se este é o espaço educacional que se deseja para os alunos surdos. 
A inclusão escolar de alunos surdos: o que dizem alunos, professores e intérpretes...

\section{Intérpretes de língua de sinais}

As questōes acerca do papel do intérprete educacional apontadas nas entrevistas mostram que é preciso intensificar os estudos nessa área, pois em vários recortes foi possível observar o quanto essa atuação é pouco refletida e compreendida, o que determina dificuldades para esse trabalho. Uma questão central é definir melhor a função do intérprete educacional; figura desconhecida, nova, que, com um delineamento mais adequado (direitos e deveres do intérprete, limites da interpretação, divisão do papel de intérprete e de professor, relação do intérprete com alunos surdos e ouvintes em sala de aula, entre outros), poderia favorecer um melhor aproveitamento deste profissional no espaço escolar.

A literatura aponta que no contexto escolar, especialmente aquele que envolve crianças mais novas, é impossível desempenhar um papel estritamente de intérprete (Antia \& Kreimeiyer, 2001). O intérprete participa das atividades, procurando dar acesso aos conhecimentos e isso se faz com tradução, mas também com sugestóes, exemplos e muitas outras formas de interação inerentes ao contato cotidiano com o aluno surdo em sala de aula. Todavia, se este papel não estiver claro para o próprio intérprete, professores, alunos e aluno surdo, o trabalho torna-se pouco produtivo, pois se desenvolve de forma insegura, com desconfiança, desconforto e superposições.

É preciso reconhecer que a presença do intérprete em sala de aula tem como objetivo tornar os conteúdos acadêmicos acessíveis ao aluno surdo. Entretanto, o objetivo último do trabalho escolar é a aprendizagem do aluno surdo e seu desenvolvimento em conteúdos acadêmicos, de linguagem, sociais, entre outros. A questão central não é traduzir conteúdos, mas torná-los compreensíveis, com sentido para o aluno. Deste modo, alguém que trabalhe em sala de aula, com alunos, tendo com eles uma relação estreita, cotidiana, não pode fazer sinais - interpretando - sem se importar se está sendo compreendido, ou se o aluno está aprendendo. Nessa experiência, o interpretar e o aprender estão indissoluvelmente unidos e o intérprete educacional assume, inerentemente ao seu papel, a função de também educar o aluno. Isso é premente no ensino fundamental, onde se atendem crianças que estão entrando em contato com conteúdos novos e, muitas vezes, com a língua de sinais, mas deve estar presente também em níveis mais elevados de ensino, porque se trata de um trabalho com finalidade educacional que pretende alcançar a aprendizagem. 
A questão da falta de um planejamento conjunto, da falta de um trabalho de equipe e de uma concepção mais clara do que signifique aceitar um aluno surdo em sala de aula também foi trazida pelas intérpretes. Elas se referem a tentar fazer o melhor possível num espaço adverso e cheio de dificuldades de relação, já que muitas vezes o professor não assume seu papel diante do aluno surdo, delegando funções a elas ou propondo atividades que não fazem qualquer sentido para este aluno. Falam de si mesmas como excluídas do processo educacional, à margem, buscando fazer, apesar disso, o melhor possível para que o aluno surdo desenvolva suas potencialidades no espaço escolar. Discussões constantes sobre a tarefa de cada um no espaço inclusivo, atribuiçôes e trocas de percepçôes se mostram essenciais e são um primeiro passo para uma convivência tranqüila e que possa trazer ganhos efetivos ao aluno surdo.

Seus depoimentos relevam ainda que tanto a escola quanto os professores conhecem muito pouco sobre a surdez e suas peculiaridades, não compreendendo adequadamente o aluno surdo, sua realidade e suas dificuldades de linguagem etc.

Levantou-se também nas entrevistas a importância de haver um espaço para atualização do aprendizado de língua de sinais por parte das intérpretes, para discussōes sobre o uso adequado desta língua no espaço pedagógico. Esta é uma questão abordada em outras pesquisas e foco de atenção em muitas experiências inclusivas (Napier, 2002). Todavia, no Brasil, esta questão é percebida pelos intérpretes que realizam este trabalho, mas pouco ou nada é feito para suprir esta necessidade.

Essas considerações indicam a importância de se realizarem estudos direcionados para a inclusão de alunos surdos com inserção de intérpretes de Língua Brasileira de Sinais em sala de aula, na tentativa de avaliar como este processo vem ocorrendo, como já se faz em outros países, e até mesmo avaliar os efeitos de tal processo nas séries iniciais de escolarização.

\section{Reflexões sobre a inclusão escolar do aluno surdo}

A questão das dificuldades de comunicação dos surdos é bastante conhecida, mas, na realidade brasileira, as leis $(10.436,24$ de abril de 2002, que dispõe sobre a língua de sinais brasileira, e mais recentemente o Decreto 5626/05, que regulamenta as leis 10.098/94 e 
A inclusão escolar de alunos surdos: o que dizem alunos, professores e intérpretes...

10.436/02 e orienta ações para o atendimento à pessoa surda) e este conhecimento não têm sido suficientes para propiciar que o aluno surdo, que freqüente uma escola de ouvintes, seja acompanhado por um intérprete. Além disso, a presença do intérprete de língua de sinais não é suficiente para uma inclusão satisfatória, sendo necessária uma série de outras providências para que este aluno possa ser atendido adequadamente: adequação curricular, aspectos didáticos e metodológicos, conhecimentos sobre a surdez e sobre a língua de sinais, entre outros.

Assim, muitos dos aspectos da realidade escolar de inclusão apontados neste estudo não são singulares, como pode parecer em princípio. A presença de um intérprete de LIBRAS em escolas brasileiras é, sem dúvida, algo ainda pouco comum. Contudo, a desinformação dos professores e o desconhecimento sobre a surdez e sobre modos adequados de atendimento ao aluno surdo são freqüentes. A prática de muitos anos de acompanhamento de crianças surdas permite afirmar que, infelizmente, a maior parte das inclusões escolares de surdos é pouco responsável. A escola se mostra inicialmente aberta a receber a criança (também porque há a força da lei que diz que a escola deve estar aberta à inclusão), discute as características da criança no momento de sua entrada e, depois, a insere na rotina, sem qualquer cuidado especial. Em geral, com o passar do tempo, a criança parece bem, já que não apresenta muitos problemas de comportamento, e todos parecem achar que está tudo certo: a) a escola não se preocupa mais com a questão, porque se preocupar significaria buscar outras ajudas profissionais (intérprete, educador surdo, professor de apoio etc.), e a escola pública brasileira, em geral, não conta nem com a equipe básica de educadores para atender as necessidades dos alunos ouvintes; b) os professores, que percebem que o aluno não evolui, mas não sabem o que devem fazer, por falta de conhecimento e preparo; c) os alunos ouvintes, que acolhem, como podem, a criança surda sem saber bem como se relacionar com ela; d) o aluno surdo, que, apesar de não conseguir seguir a maior parte daquilo que é apresentado em aula, simula estar acompanhando as atividades escolares, pois afinal todas aquelas pessoas parecem acreditar que ele é capaz; e) a família, que sem ter outros recursos precisa achar que seu filho está bem naquela escola.

Ao final de anos de escolarização, a criança recebe o certificado escolar sem que tenha sido minimamente preparada para alcançar os conhecimentos que ela teria potencial para alcançar (em muitos casos, termina a oitava série com conhecimentos de língua portuguesa e 
matemática compatíveis com a terceira série). Esta realidade é gravíssima e tem se repetido no Brasil, a cada ano. Torna-se urgente intervir e modificar estes fatos.

A presença de um intérprete de língua de sinais em sala de aula pode minimizar alguns aspectos deste problema, em geral, favorecendo uma melhor aprendizagem de conteúdos acadêmicos pelo aluno, que teria ao menos acesso (se conhecesse a língua de sinais, ou pudesse adquiri-la) aos conteúdos trabalhados. Todavia, este aluno continua inserido em um ambiente pensado e organizado para alunos ouvintes. Para que este ambiente se torne minimamente adequado às necessidades de alunos surdos, são necessárias mudanças e adaptações que se encontram distantes de serem realizadas.

O aluno surdo é usuário de uma língua que nenhum companheiro ou professor efetivamente conhece. Ele é um estrangeiro que tem acesso aos conhecimentos de um modo diverso dos demais e se mantém isolado do grupo (ainda que existam contatos e um relacionamento amigável). A questão da língua é fundamental, pois, sem ela, as relações mais aprofundadas são impossíveis, não se pode falar de sentimentos, de emoções, de dúvidas, de pontos de vista diversos. As entrevistas revelam que a relação do aluno surdo com os demais se limita a trocas de informações básicas, que são enganosamente "imaginadas por todos" como satisfatórias e adequadas. Ele, por não conhecer outras experiências, só pode achar que este ambiente em que vive é bom: tem amigos, vai à escola todos os dias, é bem tratado e tem a intérprete. Todavia, tudo isso se mostra precário, longe daquilo que seria desejável para qualquer aluno de sua idade.

Outro ponto importante, no que tange às questões de desenvolvimento, é que o aluno surdo, como qualquer criança que freqüenta o ensino fundamental, está em processo de desenvolvimento de linguagem, de processos identificatórios, de construção de valores sociais e afetivos, entre outros. É na escola que as crianças aprendem ou aperfeiçoam formas de narrar, de descrever, modos adequados de usar a linguagem em diferentes contextos, ampliando seu conhecimento lingüístico, e experimentam regras de convivência social, regras de formação de grupo e de valores sociais fundamentais para a adaptação da vida em sociedade. É também na escola que emoçôes e afetos são vividos de forma mais aberta, menos protegida, propiciando sucesso, insucesso, ciúmes, competição, raiva; sentimentos importantes de serem conheci- 
A inclusão escolar de alunos surdos: o que dizem alunos, professores e intérpretes...

dos e exercitados para o convívio social. Além disso, é nesta etapa da vida que os processos identificatórios se consolidam e o aluno surdo, sozinho no ambiente escolar, em sua condição de surdez, pode, por isso mesmo, enfrentar uma série de dificuldades.

Shaw e Jamienson (1997) discutem que os discursos de sala de aula revelam papéis sociais e culturais nas interações que podem ser diferentes em muitos aspectos daquilo que tratam normalmente os discursos familiares. Assim, o discurso do professor guia a atenção dos alunos para tarefas relevantes, avaliando suas respostas e sua adequação. Além disso, muito do que é dito para outro aluno em uma explicação ou discussão é ouvido pelo grupo e constitui um conhecimento adquirido, ainda que não diretamente voltado para este ou aquele sujeito; neste ambiente, onde um pergunta, outro responde e outro ouve, se constroem muitas regras de conhecimento social e afetivo importantes para o desenvolvimento da criança.

Nesse sentido, crianças surdas possuem estratégias de comunicação muito peculiares, pois a maioria vem de lares ouvintes que não possibilitam um desenvolvimento lingüístico no patamar das crianças ouvintes. Assim, elas partem de uma exposição e de estratégias de linguagem diferentes, estando expostas a um ambiente que usa simultaneamente pistas visuais e auditivas, impondo a elas opções, dividindo sua atenção. Em uma sala de aula para alunos ouvintes, isso se reproduz, já que o professor passa as informaçóes de acordo com aquilo que está acostumado, sendo mais adequado aos ouvintes que às crianças surdas. Desse modo, a criança surda está presente, mas está perdendo uma série de informações fundamentais sobre questões de linguagem, sociais e afetivas que lhe escapam justamente por sua condição de ser usuária de outra língua, tendo acesso aos conteúdos apenas pela mediação do intérprete. A criança surda tem um interlocutor único que usa uma linguagem filtrada, escolar e própria para a tradução (Teruggi, 2003), sem outros modelos, sem trocas, sem contato com tudo que circula entre coetâneos. Trata-se de uma experiência restritiva, em um momento fundamental de seu desenvolvimento, que precisa ser considerada.

A situação do aluno surdo incluído faz pensar no texto de Platão, "O mito da caverna", presente no Diálogo: A República. ${ }^{2}$

(...) homens vivendo numa caverna cuja entrada se abre para a luz em toda a sua largura, com um amplo saguão de acesso. Os habitantes desta caver- 
na têm as pernas e o pescoço amarrados de tal modo que não podem mudar de posição e olhem apenas para o fundo da caverna, onde há uma parede. Bem em frente da entrada da caverna existe um pequeno muro da altura de um homem e, por trás desse muro, se movem homens carregando sobre os ombros estátuas trabalhadas em pedra e madeira, representando os mais diversos tipos de coisas. E lá no alto brilha o sol. A caverna também produz ecos e os homens que passam por trás do muro falam de modo que suas vozes ecoem no fundo da caverna (...). Se fosse assim, certamente os habitantes da caverna nada poderiam ver além das sombras das pequenas estátuas projetadas no fundo da caverna e ouviriam apenas o eco das vozes. Entretanto, por nunca terem visto outra coisa, eles acreditariam que aquelas sombras, que eram cópias imperfeitas de objetos reais, eram a única e verdadeira realidade e que o eco das vozes seria o som real das vozes emitidas pelas sombras (...).

Assim, o aluno surdo, seus companheiros e professores (como os entrevistados neste estudo) parecem ver apenas as sombras e os ecos e não compreendem que as relações escolares poderiam se dar de modo diferente. Ainda, seguindo o mito criado por Platão:

Suponhamos, agora, que um daqueles habitantes consiga se soltar das correntes que o prendem. Com muita dificuldade e sentindo-se freqüentemente tonto, ele se voltaria para a luz e começaria a subir até a entrada da caverna. Com muita dificuldade e sentindo-se perdido, ele começaria a se habituar à nova visão com a qual se deparava. Habituando os olhos e os ouvidos, ele veria as estatuetas moverem-se por sobre o muro e, após formular inúmeras hipóteses, por fim compreenderia que elas possuem mais detalhes e são muito mais belas que as sombras que antes via na caverna, e que agora lhes parece algo irreal ou limitado. Suponhamos que alguém o traga para o outro lado do muro. Primeiramente, ele ficaria ofuscado e amedrontado pelo excesso de luz; depois, habituando-se, veria as várias coisas em si mesmas; e, por último, veria a própria luz do sol refletida em todas as coisas. Compreenderia, então, que estas e somente estas coisas seriam a realidade e que o sol seria a causa de todas as outras coisas.

Para ver e saber o que realmente se passa, como podem se dar as relações em uma sala de aula entre alunos surdos e ouvintes, professores e alunos que vivenciam esta experiência de inclusão precisariam conhecer algo diverso, conhecer melhor a surdez e sua realidade, de modo a refletir sobre o que têm vivido. "O mito da caverna" termina dizendo que: 
A inclusão escolar de alunos surdos: o que dizem alunos, professores e intérpretes...

(...) Mas ele se entristeceria se seus companheiros da caverna ficassem ainda em sua obscura ignorância acerca das causas últimas das coisas. Assim, ele, por amor, voltaria à caverna a fim de libertar seus irmãos do julgo da ignorância e dos grilhões que os prendiam. Mas, quando volta, ele é recebido como um louco que não reconhece ou não mais se adapta à realidade que eles pensam ser a verdadeira: a realidade das sombras. E, então, eles o desprezariam (...).

O texto de Platão pode iluminar alguns pontos das discussões aqui apresentadas. $\mathrm{Na}$ situação da escola inclusiva, não são os alunos surdos ou os alunos ouvintes os responsáveis por voltarem para a caverna e tentarem convencer seus companheiros de que há uma outra realidade possível de ser vivida, pois, afinal, são crianças e seria uma responsabilidade bastante grande. Mas os profissionais envolvidos neste trabalho, especialmente os intérpretes, os professores e os pesquisadores conhecem outras realidades, a realidade da surdez, a realidade escolar, e não podem se calar, sendo responsáveis por dar a conhecer os limites e os problemas enfrentados nas “cavernas da inclusão".

\section{Sobre a educação de surdos}

A questão da inclusão não é algo que envolve apenas a surdez, mas se refere a uma reflexão mais ampla da sociedade, buscando formas de melhor se relacionar com sujeitos de outra cultura, que falam outra língua, que professam outra fé religiosa, entre outros. Trata-se de um tema muito debatido atualmente e que busca refletir sobre formas adequadas de convivência, ampliando os conhecimentos sobre a realidade cultural do outro, sem restrição ou exigência de adaptação às regras do grupo majoritário. Trata-se de uma discussão sobre os modos de convivência dos grupos humanos nas suas diferenças que não é simples e que não se mostra ainda bem resolvida, seja na esfera política, religiosa, econômica ou educacional.

Nesse cenário, a educação dos surdos é um tema polêmico que gera sempre debates acalorados, pois, de um lado, estão o respeito às questôes da diferença lingüística, à identidade surda, e os modos próprios de relação cultural (apreensão do mundo) que os sujeitos surdos têm; de outro lado, a preocupação com a inclusão deste grupo na comunidade majoritária, respeitando suas diferenças e necessidades, mas atentando para que não se constitua como uma comunidade à parte, 
marginalizada. Este debate acaba se materializando na defesa, de um lado, de escolas de surdos e, de outro, pela inserção do aluno surdo na escola de todos.

Os dados deste estudo indicam o quanto um modelo, ainda que considerado inclusivo por seus participantes, pode não ser nada inclusivo. $\mathrm{O}$ aluno surdo, apesar de presente (fisicamente), não é considerado em muitos aspectos e se cria uma falsa imagem de que a inclusão é um sucesso. As reflexões apontam que a inclusão no ensino fundamental é muito restritiva para o aluno surdo, oferecendo oportunidades reduzidas de desenvolvimento de uma série de aspectos fundamentais (lingüísticos, sociais, afetivos, de identidade, entre outros) que se desenvolvem apoiados nas interações que se dão por meio da linguagem. A não partilha de uma língua comum impede a participação em eventos discursivos que são fundamentais para a constituição plena dos sujeitos.

Desse modo, uma inclusão cuidadosa que levasse em conta os vários aspectos aqui discutidos poderia ser proveitosa para alunos surdos em níveis mais elevados de ensino, quando já tivessem melhor consolidado seus conhecimentos de linguagem, sociais e afetivos, entre muitos outros.

A experiência de inclusão parece ser muito benéfica para os alunos ouvintes que têm a oportunidade de conviver com a diferença, que podem melhor elaborar seus conceitos sobre a surdez, a língua de sinais e a comunidade surda, desenvolvendo-se como cidadãos menos preconceituosos. Todavia, o custo dessa aprendizagem/elaboração não pode ser a restrição de desenvolvimento do aluno surdo. Será necessário pensar formas de convivência entre crianças surdas e ouvintes, que tragam benefícios efetivos para ambos os grupos.

Assim, para o aluno surdo, que deve cursar o ensino fundamental, será efetivamente melhor uma escola na qual os conteúdos sejam ministrados em sua língua de domínio, que ele tenha professores e companheiros que partilhem com ele a língua de sinais, de modo a poder se desenvolver o mais plenamente possível, como é oportunizado para crianças ouvintes no ensino fundamental.

A tarefa é criar espaços educacionais onde a diferença esteja presente, onde se possa aprender com o outro, sem que aspectos fundamentais do desenvolvimento de quaisquer dos sujeitos sejam prejudicados. A escola, para além dos conteúdos acadêmicos, tem espaço para atividades 
A inclusão escolar de alunos surdos: o que dizem alunos, professores e intérpretes...

esportivas, de lazer, de artes e de criação, nas quais poderiam conviver crianças com diferentes necessidades, desde que as atividades fossem preparadas e pensadas para isso. Não se trata de inserir a criança surda nas atividades propostas para ouvintes, mas de pensar atividades que possam ser integradoras e significativas para surdos e ouvintes.

Desse modo, este estudo procura revelar problemas implicados em experiências de inclusão de alunos surdos, ainda que aparentemente 'bem sucedidas', indicando a necessidade de pensar um modelo novo de escola e não de fazer caber o aluno surdo no modelo que já está ai. Este modelo foi concebido para a semelhança e não para o acolhimento das diferenças, e se a escola pretende acolher a diferença, ela precisa ser repensada de modo a respeitar de fato as singularidades, promovendo espaços de convivência e conhecimento mútuo.

Recebido em outubro de 2005 e aprovado em fevereiro de 2006.

Notas

1. Documentos produzidos em conferência mundial, da qual participaram várias representaçōes governamentais, além da UNESCO.

2. Breve resumo do mito descrito por Platão, com base no site <www.ft.org.br/painelhtml>. Acesso em: 29 abr. 2003.

\section{Referências bibliográficas}

ANTIA, S.D.; KREIMEYER, H. The role of interpreters in inclusive classrooms. American Annals of the Deaf, Washington, DC, v. 146, n. 4, p. 355-365, 2001.

ANTIA, S.D.; STINSON, M.S. Some conclusions on the education of deaf and hard-of-hearing studentes in inclusive settings: endnote. Journal of Deaf Studies and Deaf Education, Oxford, v. 4, n. 3, p. 246248, 1999.

BOTELHO, P. Segredos e silêncios na interpretação dos surdos. Belo Horizonte: Autêntica, 1998.

BRASIL. Decreto Lei n. 339, de 22 de dezembro de 2005. Brasília, DF, 2005. 
BRASIL. Lei 10.436, de 24 de abril de 2002. Dispõe sobre a Língua Brasileira de Sinais (LIBRAS) e dá outras providências. Disponível em: <www.mec.gov.br/seesp/legislacao.shtm> Acesso em: 6 mar. 2005

BUNCH, G. An interpretation of full inclusion. American Annals of the Deaf, Washinton, DC, v. 139, n. 2, p. 150-152, 1994.

COHEN, O.P. An administrator's view in inclusion for deaf children. American Annals of the Deaf, Washington, DC, v. 139, n. 2, p. 159-161, 1994.

DECLARAÇÃO de Salamanca e linhas de ação sobre necessidades educativas especiais. Brasília, DF: CORDE, 1994.

GÓES, M.C.R. Linguagem, surdez e educação. Campinas: Autores Associados, 1996.

KIRCHNER, C.J. Co-enrolment as an inclusion model. American Annals of the Deaf, Washington, DC, v. 139, n. 2, p. 163-164, 1994.

LACERDA, C.B.F. A inserção da criança surda em classe de crianças ouvintes: focalizando a organização do trabalho pedagógico. In: REUNiĀo ANUAl DA ANPED, 23, 2000, Caxambú. Anais... Caxambú: ANPED, 2000. Disponível em: <www.anped.org.br> Acesso em: 2000.

LAPLANE, A.L.F. Notas para uma análise dos discursos sobre inclusão escolar. In: Góes, M.C.R.; Laplane, A.L.F. (Org.). Políticas e práticas de educação inclusiva. Campinas: Autores Associados, 2004. p. 5-20.

MAZZOTA, M.J.S. Educação especial no Brasil: história e políticas. São Paulo: Cortez, 1996.

NAPIER, J. University interpreting: linguistic issues for consideration. Journal of Deaf Studies and Deaf Education, Oxford, v. 7, n. 4, p. 281301, 2002.

SASSAKI, R.K. Inclusão: construindo uma sociedade para todos. Rio de Janeiro: WVA, 1997.

SHAW, J.; JAMIESON, J. Patterns of classroom discourse in an integrated, interpreted elementary school setting. American Annals of the Deaf, Washington, DC, v. 142, n. 1, p. 40-47, 1997. 
A inclusão escolar de alunos surdos: o que dizem alunos, professores e intérpretes...

SILVEIRA BUENO, J.G. A educação do deficiente auditivo no Brasil. In: TENDENCIAS e desafios da educação especial. Brasília, DF: SEESP, 1994.

TERUGGI, L.A. Una scuola, due lingue: l'esperienza di bilinguismo della scuola dell'infanzia ed elementare di Cossato. Milano: Franco Angelli, 2003.

VIGOTSKI, L.S. A construção do pensamento e da linguagem. São Paulo: Martins Fontes, 2001. 